\section{The Lead Reference Centre}

\section{Continued from page 89}

The Lead Reference Centre has been established within the Environment Protection Authority to coordinate the NSW Government's policy response to lead hazards in the environment and the implementation of the Lead Management Action Plan. It is funded until June 1999 by six NSW Government agencies: the Department of Housing, the Department of Public Works and Services, the Environment Protection Authority, the NSW Health Department, Roads and Traffic Authority and the WorkCover Authority. Its goal is to achieve a lead-safe NSW by minimising the health, environmental and economic impacts of lead contamination and other lead hazards for all population groups, occupations and ecosystems. A reduction in the impact of lead contamination will result in the continuing reduction of blood lead levels in the population.

The Lead Reference Centre has a broad role in coordinating the development, evaluation and reporting on NSW Government initiatives and policy responses across all levels of the NSW Government, as well as the management of lead hazards by the community, the private sector and industry. To support this effort, the centre will work with appropriate NSW Government agencies and the private sector to develop Statewide research, public education and industry training programs. The Lead Reference Centre will coordinate the development of a broad policy response and a large number of related standards, methods and guidelines required for the effective management of lead hazards in NSW.

Major projects of relevance to health care professionals include:

\footnotetext{
- the development of guidelines to manage lead hazards for environmental health officers; running regional briefing programs on lead for health and planning officers within local government, PHUs, WorkCover and the EPA; working with the Royal College of General Practitioners to develop lead teaching materials; the development of a major community education campaign planned for early 1998, targeting parents, renovators and lead industry workers; and the dissemination of educational materials for health care professionals through the health networks.
}

The Lead Reference Centre has six staff and is located with the Environmental Health, Food and Nutrition Branch of the NSW Health Department in the grounds of the Gladesville Hospital.

\section{A GUIDE FOR HEALTH CARE PROFESSIONALS ON LEAD}

Richard Birdsey

Lead Reference Centre

$\lceil\mathrm{h}$

he first major publication developed by the Lead

Reference Centre is Lead Safe: A guide for health care professionals. The booklet was launched by the Minister for the Environment, Ms Pam Allan, in September, and has been distributed through the NSW health network by the NSW Health Department's Better Health Centre.

The guide is aimed at a range of health care professionals, including general practitioners, specialists, environmental health officers, early childhood nurses and parent educators. Information is provided on lead issues facing health care professionals, including:
- identifying groups vulnerable to the effects of lead, such as pregnant women, young children, renovators and lead industry workers;
믐 sources of environmental lead contamination; health effects of lead and how to identify them; testing for lead; and management and prevention of exposures (this includes guidelines based on the National Health and Medical Research Council action guidelines).

A comprehensive information section provides health care professionals with advice to give to patients on what to do to reduce their exposure to lead. A plain-English patient fact sheet - Lead, your health and the environment - has been developed to accompany the booklet.

Feedback provided by focus groups indicated that most health care professionals are deluged with information and would probably not read a large booklet. To assist readers, key information has been summarised into a single short section at the front of the booklet. Important points in the summary are cross-referenced to the main body of the text, where they are expanded on. This enables the user to find out more about topics of interest quickly and easily. A comprehensive reading list on lead and a directory of contacts for more information is also provided.

Copies of the booklet and accompanying fact sheet can be obtained by contacting the NSW Environment Protection Authority's Pollution Line on 131555 during business hours. 